\title{
Scaling from process timescales to daily time steps: A distribution function approach
}

\author{
D. D. Kandel, A. W. Western, and R. B. Grayson \\ Cooperative Research Centre for Catchment Hydrology and Centre for Environmental Applied Hydrology, \\ Department of Civil and Environmental Engineering, University of Melbourne, Melbourne, Victoria, Australia \\ Received 30 May 2004; revised 11 October 2004; accepted 12 November 2004; published 2 February 2005.
}

[1] A new temporal scaling method applicable to many rainfall-runoff-erosion models is presented. The method is based on the probability distribution approach used in a number of spatial hydrological models, and it uses statistical distributions of rainfall intensity to represent subdaily intensity variations in a daily time step model. This allows the effect of short timescale nonlinear processes to be captured while modeling at a daily time step, which is often attractive due to the wide availability of total daily rainfall data. The approach relies on characterizing the rainfall intensity variation within a day using a probability distribution function (pdf). This pdf is then modified by various linear and nonlinear processes typically represented in hydrological and erosion models. The statistical description of subdaily variability is thus propagated through the model, allowing the effects of variability to be captured in the simulations. This results in pdfs of various fluxes, the integration of which over a day gives respective daily totals. The method is tested using 42 plot years of daily runoff and erosion plot data from field studies in different environments from Australia and Nepal. Significant improvements in the simulation of surface runoff and erosion are achieved, compared with a similar model using average daily rainfall intensities. The probability-based model compares well with a subhourly $(2$ and $6 \mathrm{~min})$ model using similar process descriptions. This suggests that the probability-based approach captures the important effects of sub-time step variability while utilizing commonly available information. It is also found that the model parameters are more robustly defined using the probabilitybased approach compared with the daily effective parameter model. This suggests that the probability-based approach may offer improved model transferability spatially (to other areas) and temporally (to other periods).

Citation: Kandel, D. D., A. W. Western, and R. B. Grayson (2005), Scaling from process timescales to daily time steps: A distribution function approach, Water Resour. Res., 41, W02003, doi:10.1029/2004WR003380.

\section{Introduction}

[2] Scaling is a fundamental problem in hydrologic and erosion modeling. Variability, nonlinearity and the interacting nature of processes over various scales significantly influences the mechanics of surface runoff generation, erosion/deposition, and sediment production at all scales [Kirkby, 2001]. In particular, the temporal dynamics of precipitation are strong controls on surface runoff generation and the resulting soil erosion. This is due to the nonlinear nature of infiltration, soil detachment, and transport processes. These processes have characteristic timescales of minutes. Physically based models (e.g., CASC2D [Downer et al., 2002], EUROSEM [Morgan et al., 1998], GUEST [Yu and Rose, 1999], MEDALUS [Kirkby et al., 1998], SHETRAN [Bathurst et al., 1998], and WEPP [Foster et al., 1995]) can describe detailed processes at fine temporal scales but they are data intensive. Models are often applied with daily time steps with the support of daily rainfall data, leading to a mismatch in timescales that has

Copyright 2005 by the American Geophysical Union. 0043-1397/05/2004WR003380 important implications for model application [e.g., Beven, 1993; Blöschl and Sivapalan, 1995; Grayson et al., 1993]. Methods to bridge this mismatch of scales and that take the underlying process characteristics into account are needed to improve model performance.

[3] Surface erosion is mainly controlled by the impact energy of falling raindrops on the soil surface and by surface runoff transporting sediment entrained in the flow [Foster and Martin, 1969; Foster et al., 1977; Hairsine and Rose, 1992; Meyer et al., 1975; Young and Wiersma, 1973]. Various studies [e.g., Bennett, 1974; Cook, 1936; David and Beer, 1975; Flanagan et al., 1988; Foster and Meyer, 1975; Meyer and Wischmeier, 1969; Meyer and Monke, 1965; Smith and Wischmeier, 1957] have described the processes involved, which typically occur at timescales of minutes. The effect of rainfall characteristics on soil erosion was reported since the inception of soil erosion by water [e.g., Ekern, 1950; Ellison, 1944; Neal, 1938; Wischmeier and Smith, 1958] and the importance of subhourly rainfall intensity in erosion modeling was recognized by the EI30 concept used in the universal soil loss equation (USLE) [e.g., Wischmeier and Smith, 1965, 1978; Wischmeier, 1972]. A modification of the USLE [e.g., Kinnell and Risse, 
1998] assumes that sediment concentration for an event depends on the energy per unit quantity of rain and $I_{30}$ (the maximum 30-min intensity) as a measure of the effective intensity. Other studies have shown that both (infiltration excess) surface runoff and erosion are modeled better by using fine time step rather than daily time step models [e.g., Kandel, 2003; Kandel et al., 2004; Rose and Yu, 1998; Socolofsky et al., 2001]. Particularly, peak rates of rainfall for rainfall-runoff modeling, and peak rates of both rainfall and runoff for erosion modeling are recognized as the most important hydrologic variables [e.g., Foster et al., 1977, 1995; Yu et al., 1998; Williams, 1975]. All these studies indicate that subdaily variability of rainfall intensity is important and quite short timescales should be represented in models to capture this variation. It is clear that the mismatch between the daily temporal resolution of many observations of rainfall and process timescales reduces model performance in many applications, and severely affects the interpretation and selection of parameter values [e.g., Cameron et al., 2001; Mertens et al., 2002]. Andersen et al. [2001] argued that the constraint in process-based modeling at larger scales is the limited availability of high resolution input data required to model subscale heterogeneities and variabilities in space and time.

[4] Variation in rainfall intensity is the key driver of subdaily variations in runoff and erosion processes. While the details of the intraday temporal pattern of rainfall at a location are often unknown, the statistical behavior of the intensity variations can be predicted with reasonable accuracy, given the daily rainfall depth. The subdaily intensity variability can be derived using empirical relationships (between the distribution parameters and daily rainfall totals or other predictive variables) developed from climatic data for the same region [Kandel, 2003; Kandel et al., 2004]. Therefore there is scope for statistical approaches to bridge between the observations and the processes, by enabling representation of some components of variability that dominate the process response. There are essentially two groups of statistical approaches. The first approach relies on generating a statistically realistic rainfall pattern for the day (i.e., disaggregating or downscaling the daily rainfall total) and then running a high temporal resolution model. Various daily rainfall disaggregation schemes have been developed [e.g., Boughton, 2000; Connolly et al., 1998; Glasbey et al., 1995; Hershenhorn and Woolhiser, 1987; Econopouly et al., 1990; Socolofsky et al., 2001], ranging from simple one parameter schemes to sophisticated multiparameter schemes. Once the daily rainfall has been disaggregated to short timescales, it can be input into traditional process based models. This has been found to significantly improve the performance and prediction efficiency of models [e.g., Kandel, 2003; Kandel et al., 2004; Mertens et al., 2002; Socolofsky et al., 2001]. While this approach is potentially applicable to many models, it has disadvantages in that it does not work directly at the scale of the available information; it requires a tuned rainfall disaggregation scheme and is computationally expensive. Therefore methods that capture the effect of subdaily variability while operating with daily data at a daily time step would be desirable.

[5] The second approach is to model the impact of various processes on the statistical distribution of fluxes within the time step directly at the timescale supported by the available data (e.g., daily). In the spatial context, models such as TOPMODEL [Beven and Kirkby, 1979] [see also Sivapalan and Wood, 1986; Beven, 1995] and VIC [Wood et al., 1992] [see also Sivapalan and Woods, 1995] use a distribution function approach for saturation excess runoff, as does the infiltration model of Hawkins and Cundy [1987] [see also Yu et al., 1997, 1998], which is part of the rainfallrunoff model used in this paper. Various studies [e.g., Moore and Clarke, 1981, 1983; Moore, 1985] have provided a valuable conceptual basis for application of the probabilitydistributed approach spatially. In using a statistical distribution, instead of the actual pattern, it is assumed that details of the pattern are less important than the distribution of values.

[6] This study develops a new method that effectively scales between process timescales (e.g., minutes) and typical measurement timescales (e.g., daily) using the probability distribution function and is applicable to many hydrological model structures. Conceptually, this method can be considered as a temporal analogue to the probability distribution function approach in the space domain of Moore [1985]. Specifically, we use the cumulative distribution function (cdf) of rainfall intensity within the day as input and we model the cdfs of surface runoff and erosion fluxes within a day. This effectively incorporates the impact of the rainfall variability on the surface runoff and erosion processes while retaining the computational efficiency of the daily time step models and matching common measurement timescales. The method is tested at plot scale in different environments using runoff and erosion plot data from Australia and Nepal. The probability-based model is compared with both daily and subhourly (2 min for Nepal and $6 \mathrm{~min}$ for Australia) time step models. All three models use the same basic process descriptions and storage configuration.

[7] The paper first deals with the general model structure and the processes, followed by a description of the probability distribution function model, including a method to calculate the cdf of surface runoff and erosion fluxes, given the rainfall cdf, the integration of which gives daily averages. We then describe the specific rainfall cdf model used in this study to represent the subdaily variability of rainfall intensities. This is followed by a description of analytical methods and analysis of the simulation results of the probability-based model, in terms of general model performance, as well as parameter reliability and plausibility. The results of the probability-based model are compared with those of the daily and subhourly models, followed by a discussion on implications of the probabilistic approach to temporal scaling in modeling hydrological processes.

\section{Model Description}

\subsection{Basic Model Structure and Process Descriptions}

[8] Three different sets of model runs are used in this paper, all of which use the same basic model structure and process descriptions. The three sets differ in how temporal variations of rainfall are incorporated. The simulations that are the main focus of the paper use a daily time step and rainfall cdfs to describe unresolved temporal variations within the day. This approach is referred to as the probability-based approach and it is described in detail in the 


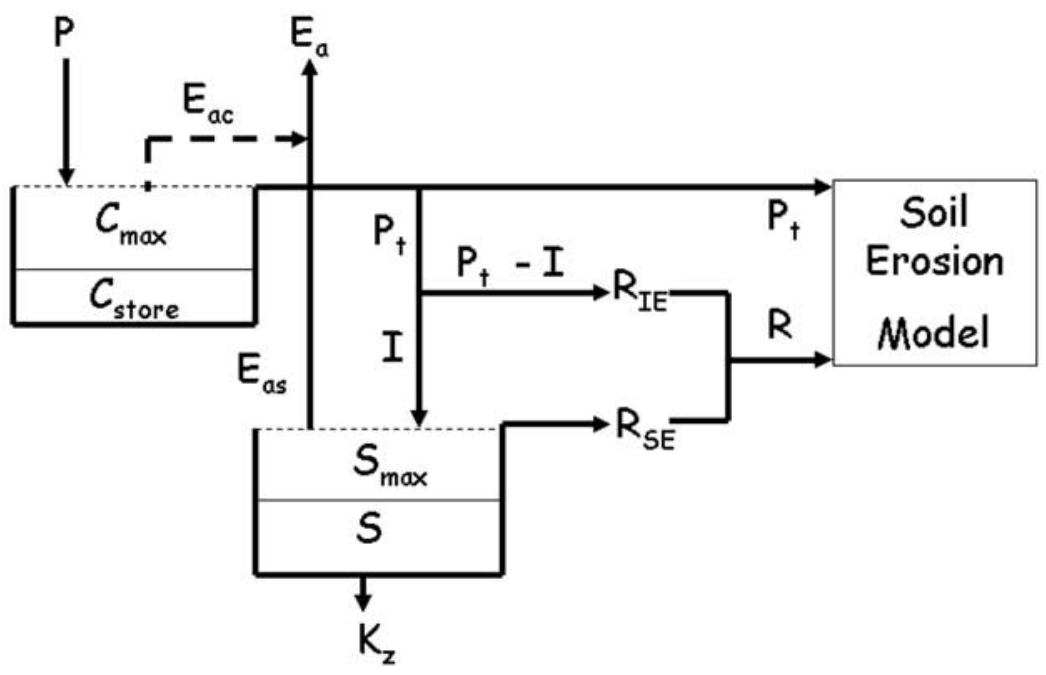

Figure 1. A schematic diagram of the rainfall-runoff-erosion model. The rainfall-runoff model has two stores, canopy and soil with respective capacities of $C_{\max }$ and $S_{\max }$, simulates both infiltration excess $\left(R_{I E}\right)$ and saturation excess $\left(R_{S E}\right)$ runoff generation, and provides throughfall $\left(P_{t}\right)$ and runoff $(R)$ as input to an erosion model. Refer to notation section for details on symbols and other variables.

following section. The two other sets of model simulations use a conventional time stepping approach where the rainfall intensity is assumed to be constant within the time step. The first of these is referred to as the subhourly model and this uses 2- or 6-min time steps with rainfall intensities observed using tipping bucket rain gauges at this temporal resolution. The final set is referred to as the daily model, for which rainfall intensities are averaged over a day.

[9] The basic rainfall-runoff and erosion model used here is a hybrid that simulates interception and uses the infiltration model of Hawkins and Cundy [1987] after modification by Kandel et al. [2002] to calculate the infiltration excess runoff. Saturation excess runoff is observed in some of the landscapes used in this study [e.g., Collins et al., 1998]. Although this is not an important part of the model in this study; for completeness and soil store balance that has controls on infiltration capacity, we have also incorporated a simple bucket-type storage capacity concept to enable saturation excess runoff to be simulated. The model uses a one-parameter erosion algorithm for erosion prediction. The model is shown schematically in Figure 1.

[10] The model simulates interception using a simple bucket, which overflows and produces throughfall when its capacity is exceeded. The throughfall $\left(P_{t}\right)$ rate is calculated as

$$
P_{t}=\operatorname{Max}\left\{\begin{array}{c}
0 \\
P-\frac{C_{\max }-C_{0}}{\Delta t}-E_{a c}
\end{array}\right.
$$

where $P$ is the rainfall intensity, $C_{0}$ is the initial canopy store content, $C_{\max }$ is the canopy interception store capacity, $\Delta t$ is the time step, and $E_{a c}$ is the actual canopy evaporation rate. $E_{a c}$ is assumed to occur at the potential rate, $E_{p}$, unless the effective water supply rate $\left(P+C_{0} / \Delta t\right)$ is limiting.
[11] The infiltration rate, $I$, is based on a modification of Hawkins and Cundy [1987] infiltration model and calculated as:

$$
I=I_{p}\left(1-e^{-P_{t} / I_{p}}\right)
$$

where $I_{p}$ is a soil moisture-dependent potential infiltration rate calculated as [Kandel et al., 2002]:

$$
I_{p}=I_{0}\left(\frac{S}{S_{\max }}\right)^{-a}
$$

where $S$ is the soil storage, $S_{\max }$ is the soil storage capacity, $I_{0}$ is the limiting infiltration rate under saturated conditions, and $a$ is a parameter accounting for the nonlinearity. Conceptually, $I_{0}$ represents the whole plot (not a point) and is considered to be spatially averaged over the plot area. Actual infiltration rates at plot scale are controlled jointly by the extreme rainfall intensities and by the plot-averaged potential infiltration rate $\left(I_{p}\right)$, which is expressed by equation (2).

[12] The infiltration excess runoff rate is calculated as:

$$
R_{I E}=P_{t}-I
$$

Saturation excess runoff rate is calculated as:

$$
R_{S E}=\operatorname{Max}\left\{\begin{array}{c}
0 \\
\frac{S_{0}-S_{\max }}{\Delta t}+I-E_{a s}-K_{z}
\end{array}\right.
$$

where $S_{0}$ is initial soil storage, $S_{\max }$ is soil storage capacity, $E_{a s}$ is actual evapotranspiration rate from the soil and $K_{z}$ is soil moisture-dependent drainage rate. The total runoff rate, $R$, is then obtained by adding $R_{I E}$ (equation (4)) and $R_{S E}$ (equation (5)). 


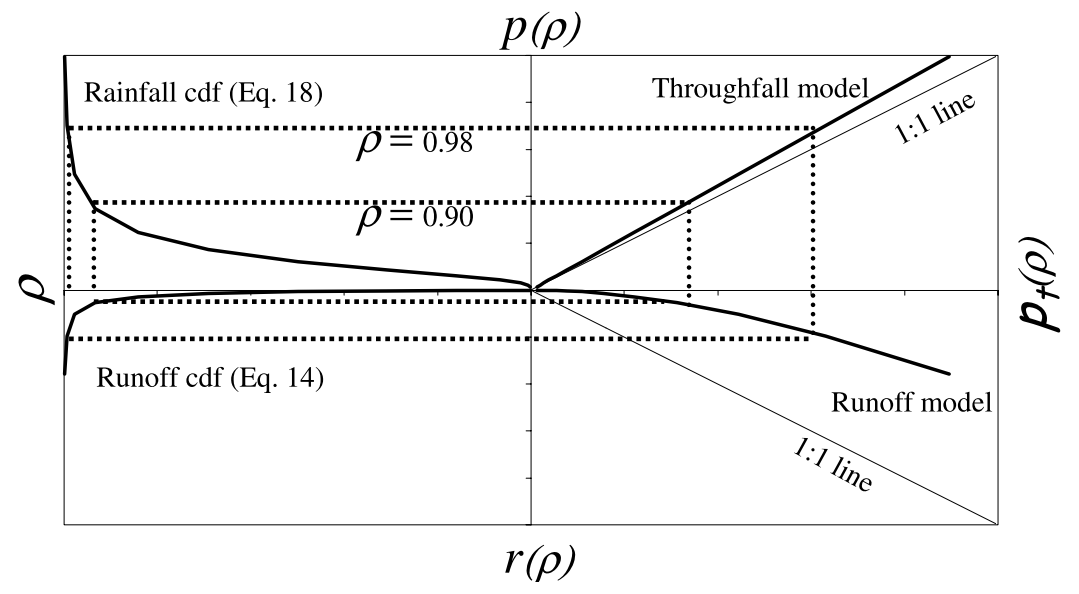

Figure 2. The process of translating cdfs of rainfall intensity into the cdfs of runoff fluxes (via the processes of throughfall and infiltration). The first quadrant shows precipitation versus throughfall. The other quadrants show the cdf plot of precipitation (fourth quadrant), infiltration (second quadrant), and runoff (third quadrant). The variables are arranged in the four quadrants so that the range of cdf values $(0$ to 1$)$ is represented by the concentric rectangles. For a given cdf (e.g., $\rho=0.90)$ the rectangle in each quadrant gives the corresponding values of rates of precipitation, throughfall, infiltration, and runoff. In a similar fashion, cdfs of erosion fluxes are obtained from the cdfs of both rainfall intensity and runoff rates.

[13] The sum of $E_{a c}$ and $E_{a s}$ gives $E_{a}$, the total loss due to evapotranspiration. For completeness, expression for $E_{a s}$ and $K_{z}$ are also included below.

$$
E_{a s}=\left(E_{P}-E_{a c}\right) \frac{S}{S_{\max }}
$$

where $E_{a s}$ is the actual evapotranspiration from land surface and $E_{p}$ is the potential evapotranspiration.

$$
K_{z}=\left\{\begin{array}{clc}
K_{s h}\left(\frac{S-S_{f c}}{S_{\max }-S_{f c}}\right)^{c} & \text { if } & S>S_{f c} \\
0 & \text { if } & S \leq S_{f c}
\end{array}\right.
$$

where $K_{z}$ and $K_{s h}$ denote the vertical seepage and the saturated hydraulic conductivity respectively, and $c$ is a calibration factor.

[14] Conceptually, surface erosion can be considered as a function of four factors: (1) soil erodibility, (2) precipitation rates (after canopy interception), (3) runoff rates, and (4) slope of the land surface. Thus at the plot scale the erosion rate can be calculated as:

$$
D_{e r}=K_{e r} P_{t} R S_{f}
$$

where $K_{e r}$ and $S_{f}$ are the spatially averaged soil erodibility and the slope factor respectively. The slope factor is estimated using a relationship developed by Liebenow et al. [1990]. Equation (8) is based on the interrill erosion algorithm of the WEPP model [Foster et al., 1995; Ghidey and Alberts, 1996; Foster et al., 1977]. Note that WEPP uses both rill and interrill erosion equations, along with many other empirical relationships for parameter estimation, but lack of detailed data, particularly the rill information, detailed soil properties and other land and crop management practices, means that there is no justification for using the full WEPP model here. This erosion algorithm is chosen here for model simplicity and parameter efficiency and also because of its ability to produce comparable estimates of daily sediment yields compared with other more complex erosion algorithms using both daily and short (minutes) time steps [Kandel et al., 2001].

[15] These model algorithms are used for both the subhourly and daily time step simulations. The subhourly and daily model simulations differ only in the temporal resolution of the rainfall input and the computational time step, and in their parameter values. For the subhourly model, observed 2-min (Nepal) and 6-min (Australia) intensities are used directly as input. The rainfall-runoff model (equations (1)(7)) is used to simulate the required runoff rates at the subhourly time steps. For the daily model, daily average rainfall intensity is input to the rainfall-runoff model to simulate the daily runoff rate. In both the subhourly and daily time step simulations, standard water budget computations (i.e., conservation of mass) are used to propagate the soil water storage state forward in time.

\subsection{Probability Distribution Function Model}

[16] The above model provides the basis for the temporal probability-based model. The basic model structure and process descriptions are the same as described in section 2.1 but in probability space. Therefore the input to this model is a cdf of rainfall intensity, rather than the actual values of rainfall intensity. The computation of distribution functions for each of the fluxes is now described for a general cdf, and then the specific distribution used to represent the rainfall intensity cdf is described. In the following, the cdfs are represented with lower case symbols, while the time step average fluxes are represented by upper case letters as defined above. The cdf of rainfall intensity within the time step is $p(\rho)$, where $\rho$ is the cumulative probability. The average throughfall rate is computed using equation (1) and it is assumed that the state of the canopy 
store (or occurrence of throughfall) is independent of the rainfall intensity. The cdf of throughfall is then given by:

$$
p_{t}(\rho)=\left(\frac{P_{t}}{P}\right) p(\rho)
$$

The infiltration rate cdf, $i(\rho)$, is calculated using a modified version of equation (2) as:

$$
i(\rho)=I_{p}\left(1-e^{-\frac{p_{t}(\rho)}{l_{p}}}\right)
$$

The average infiltration rate during the time step can then be calculated by integration.

$$
I=\int_{0}^{1} i(\rho) d \rho
$$

The infiltration excess runoff distribution, $r_{I E}(\rho)$ can then be calculated as the difference between the throughfall and infiltration distributions.

$$
r_{I E}(\rho)=p_{t}(\rho)-i(\rho)
$$

The average rate of saturation excess runoff $\left(R_{S E}\right)$ can be calculated with equation (5) after the soil store is updated in time by adding infiltration (I). It is assumed that the occurrence of saturation excess runoff is independent of $i(\rho)$. This implies that the saturation excess runoff distribution, $r_{S E}(\rho)$ can be modeled as proportional to the infiltration distribution.

$$
r_{S E}(\rho)=\left(\frac{R_{S E}}{I}\right) i(\rho)
$$

The cdf of surface runoff, $r(\rho)$, is then

$$
r(\rho)=r_{I E}(\rho)+r_{S E}(\rho)
$$

and the daily average runoff rate is

$$
R=\int_{0}^{1} r(\rho) d \rho
$$

Finally, the soil erosion cdf, $d_{e r}(\rho)$ is obtained by incorporating the throughfall and runoff rate distributions into the erosion algorithm (equation (8)) resulting in

$$
d_{e r}(\rho)=K_{e r} p_{t}(\rho) r(\rho) S_{f}
$$

This assumes that within a day, the runoff rate and rainfall intensity have a rank correlation of 1 in time i.e., the largest rainfall intensities result in the largest runoff rates without any time delay. The daily average soil erosion, $D_{e r}$ is obtained by integrating the erosion distribution.

$$
D_{e r}=\int_{0}^{1} d_{e r}(\rho) d \rho
$$

Figure 2 illustrates the translation of the rainfall cdf through the throughfall, infiltration, and runoff processes to produce the runoff cdf. It is worth noting that the approach used for rainfall scaling here is general and could be applied to many (but not all) rainfall-runoff models.

[17] The integration of the distribution functions in equations (11), (15), and (17) is performed numerically. This adds computational demand compared with the daily time step model but is computationally efficient compared to the subhourly model. For computational efficiency, it is desirable to minimize the number of probability increments, however this will lead to some numerical error, which may reduce the model performance. Therefore the sensitivity of the distribution function model to the number of increments used to describe the cdf was tested by running the model with cdf increments of 10, 20, 30, 50, 60, 75, and 100. It was found that the runoff and erosion predictions were insensitive to the number of increments between 20 and 60 , producing similar parameter values and model performance, although the increments outside this range tended to slightly underestimate (if $\mathrm{n}<20$ ) or overestimate (if $n>60$ ) some of the observed values. For the results presented here, 24 uniform probability increments were used for the integrations of the nonzero intensity proportion of the cdf, which is equivalent to an hourly time step in terms of computational efficiency.

\subsection{Temporal Distribution of Rainfall Intensities}

[18] So far, we have described how a general cdf of rainfall can be input into the model and how this is then modified to produce cdfs of various fluxes, including runoff and erosion. Now, we discuss the specific cdf used to characterize the rainfall intensity variation in this study.

[19] Stochastic models that disaggregate daily rainfall often sample from statistical distributions [e.g., Econopouly et al., 1990; Mertens et al., 2002], which can be either standard theoretical probability distributions or empirical (i.e., data driven) probability distributions. The commonly used theoretical distributions include (but are not limited to) the exponential, gamma, beta, lognormal and generalized Pareto distributions. There is disagreement amongst researchers as to which distribution is preferred to represent temporal variability of rainfall intensities and it is likely to depend on the particular location where the model is being applied. Connolly et al. [1998] used a double exponential distribution to generate internal intensity for each event in Australia but also found that a gamma distribution fit better in some instances. Mertens et al. [2002] used the frequency distribution of 10-min resolution data for 61 years in Belgium to classify intensity into three classes for each month and incorporated the monthly distribution information of these three intensity classes into daily rainfalls by splitting the daily amount into three durations for each of the intensity class. Others [e.g., Econopouly et al., 1990; Hershenhorn and Woolhiser, 1987] used the estimated probability distributions fitted to the measured hourly data to disaggregate daily rainfall. They used four different statistical distributions with a total of 17 parameters for each season. Obviously, it is difficult to fit a single distribution for the whole year; nevertheless, Econopouly et al. [1990] reported that a single set of parameters calibrated at one station could be applied to disaggregate data at another 
Table 1. Characteristics of the Erosion Plots in Nepalese and Australian Sites ${ }^{\mathrm{a}}$

\begin{tabular}{|c|c|c|c|c|c|c|c|c|}
\hline & \multicolumn{7}{|c|}{ Nepalese Sites } & \multirow{2}{*}{$\begin{array}{c}\text { Australian } \\
\text { Sites }\end{array}$} \\
\hline & 4 & 14 & 16 & 17 & $6 a$ & $6 \mathrm{~b}$ & $14 a$ & \\
\hline Location & Baghkhor & Kubhinde & Bhetwalthok & Ghartithok & Bela & Bela & Kubhinde & Gunnedah \\
\hline Area, $\mathrm{m}^{2}$ & 99 & 103 & 97 & 95 & 61 & 102 & 100 & 100 \\
\hline Slope length, m & 19.8 & 20.6 & 12.6 & 19.0 & 13.6 & 20.4 & 20 & 40.9 \\
\hline Slope, degree & 11.5 & 15.0 & 6.7 & 9.2 & 20.4 & 14.0 & 15.0 & 4.3 \\
\hline Elevation, m & 1040 & 1010 & 1365 & 1285 & 1320 & 1345 & 1010 & 307 \\
\hline Aspect & $\mathrm{NE}$ & west & south & south & west & north & west & west \\
\hline Infiltration, ${ }^{b} \mathrm{~mm} / \mathrm{h}$ & $32 \pm 12$ & $155 \pm 43$ & $69 \pm 33$ & $120 \pm 100$ & $97 \pm 38$ & $52 \pm 36$ & $155 \pm 43$ & - \\
\hline Soil texture & loam & loam & SC-loam & S-loam & loam & loam & loam & loam \\
\hline Land use & DSL & DSL & CUT & CUT & CUT & CUT & DSL & BFL \\
\hline
\end{tabular}

${ }^{a}$ SC-loam, sandy clay loam; S-loam, sandy loam; NE, northeast; DSL, degraded sloping lands; CUT, cultivated upland terraces; BFL, bare fallow land.

${ }^{\mathrm{b}}$ Limiting infiltration rate (spatial mean \pm SD of three replicates) from double-ring infiltrometer test conducted in January 1998.

station (up to $470 \mathrm{~km}$ ) within the same season and climatic region, indicating that the regionalized parameters could be used for such studies.

[20] Although there are many rainfall distribution models, none appears clearly superior from the literature. In this study, the observed rainfall intensities were analyzed by fitting them with various theoretical distributions (one- and two-parameter exponential, two-parameter lognormal, and three-parameter generalized Pareto) and it was found that the observed data were represented better by the lognormal distribution than by others tested here. Therefore the twoparameter lognormal distribution was chosen to represent the rainfall intensity variation during the wet fraction of the day. Thus the rainfall intensity cdf can be written as:

$$
p(\rho)=\left\{\begin{array}{ccc}
0 & \text { if } & \rho<1-w \\
e^{\mu+\sigma z\left(\rho_{w}\right)} & \text { if } & \rho \geq 1-w
\end{array}\right.
$$

where $w$ is the wet fraction or raining proportion of the time step (a day here), $\mu$ and $\sigma$ are the mean and standard deviation of the natural log-transformed rainfall intensities (for the wet fraction of the day), $z($.$) is the normal standard$ variate and $\rho_{w}$ is the wet period conditional cumulative probability of rainfall intensity:

$$
\rho_{w}=\frac{\rho-(1-w)}{w}=1-\frac{1-\rho}{w}
$$

The three parameters required are $\mu, \sigma$, and $w$. In this study, the daily rainfall amount is used to calculate $\mu$ analytically as

$$
\mu=\ln \left(P_{w}\right)-\frac{\sigma^{2}}{2}
$$

where $P_{w}$ is the wet period mean rainfall intensity (i.e., $P_{t o t} / w$ ). This reduces the unknown parameters to two: $\sigma$ and $w$. When applying such a model $\sigma$ and $w$ could be calculated empirically from daily rainfall totals and other predictive variables using relationships developed from pluviograph data for the climate in question [Kandel, 2003; Kandel et al., 2004]. In this paper, values of $w$ and $\sigma$ were determined from the observed rainfall data directly, except where missing data precluded this. For periods with missing data, $w$ and $\sigma$ were calculated using empirical relationships based on observed total daily rainfall data [Kandel, 2003; Kandel et al., 2004].

\section{Description of Study Sites and Data Sets}

[21] This study uses point rainfall and plot-scale runoff and soil erosion data from the Jhikhu Khola catchment $\left(27^{\circ} 33^{\prime} 45^{\prime \prime}\right.$ to $27^{\circ} 42^{\prime} 30^{\prime \prime} \mathrm{N}, 85^{\circ} 31^{\prime} 15^{\prime \prime}$ to $85^{\circ} 42^{\prime} 30^{\prime \prime} \mathrm{E}$, elevations $=850$ to $2200 \mathrm{~m}$ ) in Nepal and from Gunnedah, New South Wales $\left(31^{\circ} 01^{\prime} \mathrm{S}, 150^{\circ} 15^{\prime} \mathrm{E}\right.$, elevation $\left.=307 \mathrm{~m}\right)$ in Australia. The Nepalese data set includes 24 plot years ( 5 plots $\times 4$ years +2 plots $\times 2$ years $=24$ plot years $)$ of daily surface runoff and erosion from seven plots located at six sites, and daily and 2-min precipitation from four meteorological stations for four years $(1997-2000)$. The Australian data set includes 18 plot years $(3$ plots $\times 6$ years $=$ 18 plot years) of event surface runoff and erosion from three replicate plots for six years (1981-1986), and daily and 6-min precipitation from one location for 6 years (1981-1986). The plots in Nepal lie on bare degraded sloping lands and cultivated midhill terraces with slope steepness ranging from $6.7^{\circ}$ to $20.4^{\circ}$ and slope length of about $20 \mathrm{~m}$. In the case of terraces, this slope length is broken into three or four sections depending on the terrace width and riser height. The plots in Australia are bare fallow and the three replicates are next to each other. These plots have a slope steepness of $4.3^{\circ}$ and are $40.9 \mathrm{~m}$ long, making them longer and flatter than the Nepalese plots. A summary of characteristics of these sites is given in Table 1 and a summary of the site-specific observed precipitation, surface runoff, and erosion is given in Table 2 . The rain gauges have precipitation resolutions of $0.224 \mathrm{~mm}$ and $0.249 \mathrm{~mm}$ per $2 \mathrm{~min}$ in Nepal and $0.1 \mathrm{~mm}$ per $6 \mathrm{~min}$ in Australia. A more detailed description of the sites, and methods of data recording and sample collection and processing were given by Kandel [1998, 2003] for the Nepalese sites and by Yu and Rosewell [2001] for the Australian site.

[22] Overall, the observations are of high quality and complete, except for a small amount of missing rainfall data ( $<2 \%$ of the data). The event-based runoff and erosion data in Australia were compiled to daily totals prior to the analysis. There were cases in which a day had more than one event and a few cases where an event lasted for more than a day. To compare with the daily simulated values, the event-based observations were accumulated to daily loads in the former case; and for those lasting more than a day, 
Table 2. Summary of Observed Data From Erosion Plot Studies in Nepal and Australia ${ }^{a}$

\begin{tabular}{|c|c|c|c|c|c|c|c|c|}
\hline Sites & $\begin{array}{c}\text { Annual } \\
\text { Rainfall, } \\
\text { mm }\end{array}$ & $\begin{array}{c}\text { Annual } \\
\text { Runoff, } \\
\text { mm }\end{array}$ & $\begin{array}{c}\text { Annual } \\
\text { Runoff } \\
\text { Coefficient }\end{array}$ & $\begin{array}{c}\text { Annual } \\
\text { Erosion, } \\
\text { t/ha }\end{array}$ & $\begin{array}{l}I_{\max } \\
\mathrm{mm} / \mathrm{h}\end{array}$ & $\underset{\mathrm{mm}}{P_{\max }}$ & $\begin{array}{l}\text { Rainy Days }{ }^{b} \\
\left(\mathrm{P}_{24} \geq 1 \mathrm{~mm}\right)\end{array}$ & Period Used \\
\hline \multicolumn{9}{|c|}{ Nepalese Sites } \\
\hline 4 & $1227(186)$ & $474(57)$ & $0.390(0.008)$ & $16.7(12.1)$ & $133(30)$ & $76(30)$ & 99 (3) & $1997-2000$ \\
\hline 14 & $1232(157)$ & 399 (67) & $0.323(0.027)$ & $23.0(17.0)$ & $135(53)$ & 74 (19) & $95(5)$ & $1997-2000$ \\
\hline 16 & $1281(112)$ & $15(8)$ & $0.012(0.007)$ & $0.9(0.7)$ & $114(54)$ & $79(22)$ & $94(5)$ & $1997-2000$ \\
\hline 17 & $1281(112)$ & $35(8)$ & $0.027(0.007)$ & $1.4(1.2)$ & $114(54)$ & $79(22)$ & $94(5)$ & $1997-2000$ \\
\hline $6 a$ & 1374 (107) & $35(2)$ & $0.025(0.002)$ & $11.1(7.2)$ & $127(0)$ & $97(30)$ & $109(11)$ & $1997-2000$ \\
\hline $6 b$ & $1374(107)$ & $146(26)$ & $0.111(0.022)$ & $23.2(9.9)$ & $127(0)$ & $97(30)$ & $109(11)$ & $1997-1998$ \\
\hline $14 \mathrm{a}$ & $1232(157)$ & $374(68)$ & $0.283(0.007)$ & $26.2(22.2)$ & $135(53)$ & 74 (19) & $95(5)$ & $1999-2000$ \\
\hline $\begin{array}{l}\text { All sites } \\
\text { collectively }^{c}\end{array}$ & 1281 (117) & $203(41)$ & $0.157(0.020)$ & $12.6(4.2)$ & $123(22)$ & $82(22)$ & $98(8)$ & $1997-2000$ \\
\hline \multicolumn{9}{|c|}{ Australian Sites } \\
\hline 1 & $595(168)$ & $98(70)$ & $0.155(0.065)$ & $94(63)$ & $67(15)$ & $70(34)$ & $59(13)$ & $1981-1986$ \\
\hline 2 & $595(168)$ & $103(75)$ & $0.162(0.074)$ & $90(73)$ & $67(15)$ & $70(34)$ & 59 (13) & $1981-1986$ \\
\hline 3 & $595(168)$ & $89(70)$ & $0.140(0.070)$ & $83(72)$ & 67 (15) & 70 (34) & 59 (13) & $1981-1986$ \\
\hline $\begin{array}{l}\text { All sites } \\
\text { collectively }^{\mathrm{c}}\end{array}$ & $595(168)$ & $96(71)$ & $0.152(0.069)$ & 89 (69) & $67(15)$ & $70(34)$ & 59 (13) & $1981-1986$ \\
\hline
\end{tabular}

${ }^{\mathrm{a}}$ For individual site, values are annual mean $(\mathrm{n}=2$ years for sites $6 \mathrm{~b}$ and $14 \mathrm{a}$ in Nepal, $\mathrm{n}=4$ years for all other sites in Nepal, and $\mathrm{n}=6$ years for Australian sites) with standard deviations in parentheses. $I_{\max }$ is maximum intensity recorded at 2-min resolution in Nepal and at 6-min resolution in Australia; $P_{\max }$ is 24 hourly maximum rainfalls.

${ }^{\mathrm{b}}$ Number of rainy days with 24-hourly rain totaling $\geq 1 \mathrm{~mm}$. In Australia, rainy days with 24-hourly rain $\geq 1 \mathrm{~mm}$ accounted for $\sim 80 \%$ of total rainy days during this period (i.e., $20 \%$ rainy days received $<1 \mathrm{~mm}$ rain).

${ }^{\mathrm{c}}$ This is annual-spatial mean of all sites within a country collectively (for Nepalese sites, $\mathrm{n}=5$ sites $\times 4$ years +2 sites $\times 2$ years $=24$, and for Australian sites, $\mathrm{n}=6$ years $\times 3$ sites $=18$ ).

the event loads were divided into daily loads in proportion to the observed daily precipitations. Potential evapotranspiration rates were assumed equal to the mean monthly potential evapotranspiration rates at all times, which were derived using the Thornthwaite model [Thornthwaite, 1948] for the Nepalese sites and taken from evapotranspiration maps for the Australian site [Chiew et al., 2002]. The annual potential evapotranspiration values are $957 \mathrm{~mm}$ (site 6), $1062 \mathrm{~mm}$ (sites 16 and 17), and $1076 \mathrm{~mm}$ (sites 4 and 14) for Nepal, and $1364 \mathrm{~mm}$ for Australia.

\section{Methods}

\subsection{Rainfall Analysis}

[23] Rainfall analysis was required to estimate $w$ and $\sigma$ for input into the probability-based model. In estimating $w$ and $\sigma$, it is important to note here that the nature of fixed period (e.g., $6 \mathrm{~min}$ ) tipping bucket rainfall records introduces an artifact into the rainfall intensity record that particularly affects low intensities. This artifact is due to the quantification of rainfall into discrete tips and has the effect of artificially reducing estimates of $w$ and $\sigma$ if these are calculated directly from the rainfall intensity record [Kandel, 2003]. To overcome this problem, we calculated the average ranking for each of the recorded intensity values within a day and then the lognormal distribution was fitted to their mean plotting positions by optimizing $w$ and $\sigma$. We also ignored the lowest recordable intensity and only fitted to days with at least four (including the lowest recordable intensity) different observed intensities. For days where the $\sigma$ and $w$ parameters could not be optimized, their values were estimated using empirical relationships with daily rainfall totals.

[24] The fitted rainfall distribution model was tested for its ability to reproduce daily totals and extreme values. The results show that daily totals are effectively reproduced but that some errors occur at the upper extreme, particularly for Australia. On average, the 90th percentile simulated intensity is $15 \%$ less and $1 \%$ less than the recorded values for Australia and Nepal respectively. This discrepancy in errors may be explained by the fact that the pluviograph data of Australia (6-min data) is three times coarser in temporal resolution than that of Nepal (2-min data).

\subsection{Model Calibration and Testing}

[25] The probability-based model was tested and the simulation results were analyzed in terms of predictive performance as well as parameter stability/reliability and plausibility. The probability-based model was also compared with a daily model and a subhourly model having the same basic model structure (equations (1)-(8)). All three models were calibrated against daily observations of runoff depth and sediment yield using a downhill simplex optimization algorithm [Nelder and Mead, 1965] and parameters were set for each experimental plot separately. The mean squared error in runoff (erosion for optimizing $K_{e r}$ ) was used as an objective function and calibration was performed with a variety of initial parameter sets to increase the probability of finding the global optimum. Of the six runoff $\left(C_{\max }, S_{\max }, I_{0}, a, K_{s h}, c\right)$ and one erosion $\left(K_{e r}\right)$ parameters, $C_{\max }$ and $K_{e r}$ were varied seasonally during calibration and the remaining five parameters were held constant for the whole simulation period. The seasonality in canopy and vegetation cover was accounted for by grouping data into different seasons. Since the climate in Nepal is dominated by monsoonal rain, the three hydrologic seasons were used for the Nepalese sites: (1) premonsoon (mid-February to mid-June), (2) monsoon (mid-June to mid-September), and (3) postmonsoon (mid-September to mid-February). The seasonality in Australia was addressed by grouping Australian data into four seasons: (1) summer (December to 
Table 3. Nash COE Values Obtained From Different Models ${ }^{\mathrm{a}}$

\begin{tabular}{|c|c|c|c|c|c|c|c|c|c|c|c|c|}
\hline \multirow[b]{3}{*}{ Sites } & \multicolumn{6}{|c|}{ Calibration } & \multicolumn{6}{|c|}{ Validation } \\
\hline & \multicolumn{3}{|c|}{ Surface Runoff } & \multicolumn{3}{|c|}{ Soil Erosion } & \multicolumn{3}{|c|}{ Surface Runoff } & \multicolumn{3}{|c|}{ Soil Erosion } \\
\hline & Prob & $2 / 6 \min$ & Daily & Prob & $2 / 6 \mathrm{~min}$ & Daily & Prob & $2 / 6 \mathrm{~min}$ & Daily & Prob & $2 / 6 \mathrm{~min}$ & Daily \\
\hline & & & & & & Nepal & & & & & & \\
\hline 4 & 0.91 & 0.95 & 0.78 & 0.82 & 0.79 & 0.67 & 0.90 & 0.93 & 0.74 & 0.44 & 0.43 & -0.84 \\
\hline 14 & 0.92 & 0.96 & 0.85 & 0.88 & 0.86 & 0.36 & 0.90 & 0.94 & 0.82 & 0.82 & 0.56 & -0.60 \\
\hline 16 & 0.64 & 0.78 & 0.53 & 0.62 & 0.30 & 0.07 & 0.53 & 0.68 & -0.49 & 0.26 & 0.24 & -0.40 \\
\hline 17 & 0.56 & 0.61 & 0.60 & 0.86 & 0.68 & 0.21 & 0.39 & 0.42 & -0.27 & 0.58 & 0.31 & -0.88 \\
\hline $6 a$ & 0.22 & 0.38 & 0.31 & 0.63 & 0.33 & 0.02 & 0.10 & 0.16 & 0.08 & 0.26 & 0.01 & -0.12 \\
\hline $6 \mathrm{~b}$ & 0.87 & 0.85 & 0.75 & 0.83 & 0.80 & 0.36 & 0.84 & 0.80 & 0.40 & 0.65 & 0.60 & 0.07 \\
\hline $14 \mathrm{a}$ & 0.92 & 0.93 & 0.86 & 0.83 & 0.89 & 0.53 & 0.90 & 0.90 & 0.71 & 0.34 & 0.52 & 0.19 \\
\hline All sites & 0.90 & 0.92 & 0.76 & 0.81 & 0.80 & 0.37 & 0.88 & 0.91 & 0.71 & 0.57 & 0.51 & -0.07 \\
\hline & & & & & & Australia & & & & & & \\
\hline 1 & 0.92 & 0.92 & 0.81 & 0.78 & 0.90 & 0.58 & 0.84 & 0.80 & 0.78 & 0.75 & 0.76 & 0.50 \\
\hline 2 & 0.91 & 0.90 & 0.81 & 0.89 & 0.90 & 0.68 & 0.82 & 0.77 & 0.75 & 0.79 & 0.68 & 0.61 \\
\hline 3 & 0.91 & 0.92 & 0.83 & 0.79 & 0.89 & 0.64 & 0.82 & 0.75 & 0.78 & 0.67 & 0.60 & 0.57 \\
\hline All sites & 0.91 & 0.91 & 0.81 & 0.82 & 0.89 & 0.62 & 0.82 & 0.76 & 0.76 & 0.73 & 0.67 & 0.54 \\
\hline
\end{tabular}

${ }^{a}$ The coefficient of efficiency $(\mathrm{COE})$ value for "all sites" represents a composite series that include each daily value at each site collectively $(\mathrm{n}=365 \times$ $24=8760$ for Nepalese and $n=365 \times 18=6570$ for Australian sites). Prob, probability-based model (daily time step); $2 / 6$ min, subhourly model ( 2 -min time step for Nepal and 6-min time step for Australia); daily, daily time step model.

February), (2) autumn (March to May), (3) winter (June to August), and (4) spring (September to November). Seasonal parameter values were held constant from year to year.

[26] To evaluate the model performance, we used a split sample calibration and cross-validation procedure. The data for each plot were split into two equal length periods. The model was calibrated for each period separately, resulting in two sets of calibrated parameters for each plot. These were then used for validation simulations during the other periods. Composite calibration series were constructed by combining the calibration simulations across both time periods and all plots separately for Nepal and Australia. Corresponding composite validation series were also constructed. Comparisons of both the calibration and validation simulations against the observations were made, allowing us to draw conclusions about overall model performance and the reduction in model performance between calibration and validation for each of the daily time step, subhourly time step and probability-based (also daily time step) models. The model performance was assessed both visually using the hydrographs/sedigraphs and statistically for its general goodness of fit in terms of bias, variance and scatter using the coefficient of efficiency (COE) of Nash and Sutcliffe [1970]. We also compared the optimized model parameters between calibration periods to assess parameter stability/ reliability and against our expectations to assess plausibility of the parameter values.

\section{Results and Discussion}

\subsection{Model Performance}

[27] The performance of the probability-based model was good for both runoff and erosion for most of the plots modeled. In calibration simulation, the $C O E$ values (collectively for all sites) for runoff were 0.90 (Nepal) and 0.91 (Australia), and for erosion were 0.81 (Nepal) and 0.82 (Australia). For ten sites in two countries, the range of $C O E$ values for runoff was 0.22 to 0.92 and for erosion was 0.62 to 0.89 . Of these, seventy percent were greater than 0.85 for runoff simulations and 0.80 for erosion simulations. In validation simulations, the overall $C O E$ values degraded to 0.88 and 0.82 for runoff, and 0.57 and 0.73 for erosion at the Nepalese and Australian sites respectively (Table 3). The runoff results in Nepal were similar between calibration and validation in terms of both bias and spread, whereas for erosion in Nepal and both runoff and erosion in Australia, both bias and spread increased from calibration to validation.

[28] Both the calibration and validation simulations for runoff and erosion showed that the probability distribution function model was a significant improvement over the daily effective parameter model and that it was almost as good as the subhourly model (Table 3 and Figures 3 and 4). As seen in Figure 3, for example, the simulation errors of the daily effective parameter model were higher than the probability-based and subhourly models. It was interesting to note that the probability-based model was able to simulate erosion better than the subhourly model despite relatively poorer runoff simulation (see simulation errors in Figure 3). It was clear from a comparison of the scatterplots of the aggregate performances of the different models for validation runs (for all the plots in Nepal and all the plots in Australia separately) that the probability-based model was able to perform as well as the subhourly model and that it was substantially better than the daily effective parameter model for validation simulations (Figure 4).

[29] There were consistent trends both between the three models and between the calibration and validation. These are also borne out by the scatterplots (Table 3 and Figure 4). In general, the performance of the probability-based model and the subhourly model were quite similar. The probability-based model performed substantially better than the daily effective parameter model (the model performance efficiency in validation (calibration) simulations improved by $17 \%(14 \%)$ in Nepal and $6 \%(10 \%)$ in Australia for runoff, and 64\% (44\%) in Nepal and 19\% (20\%) in 
Sub-hourly model
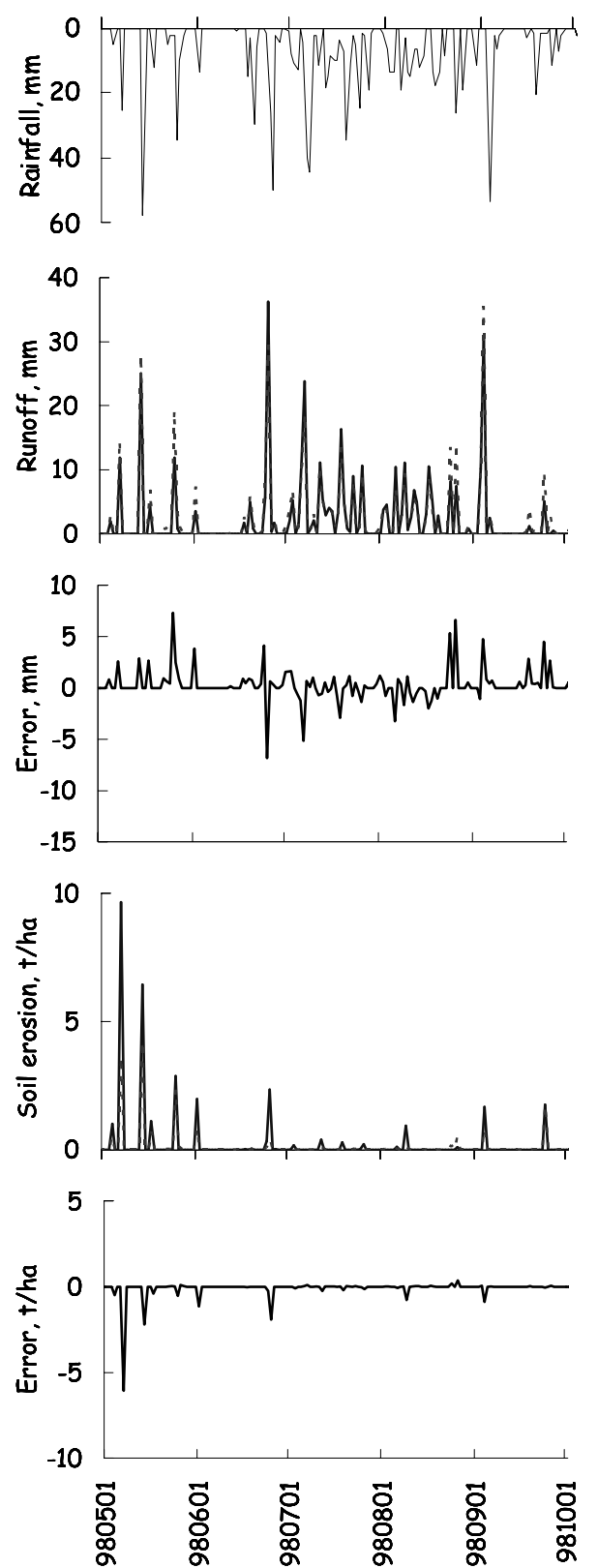

CDF model
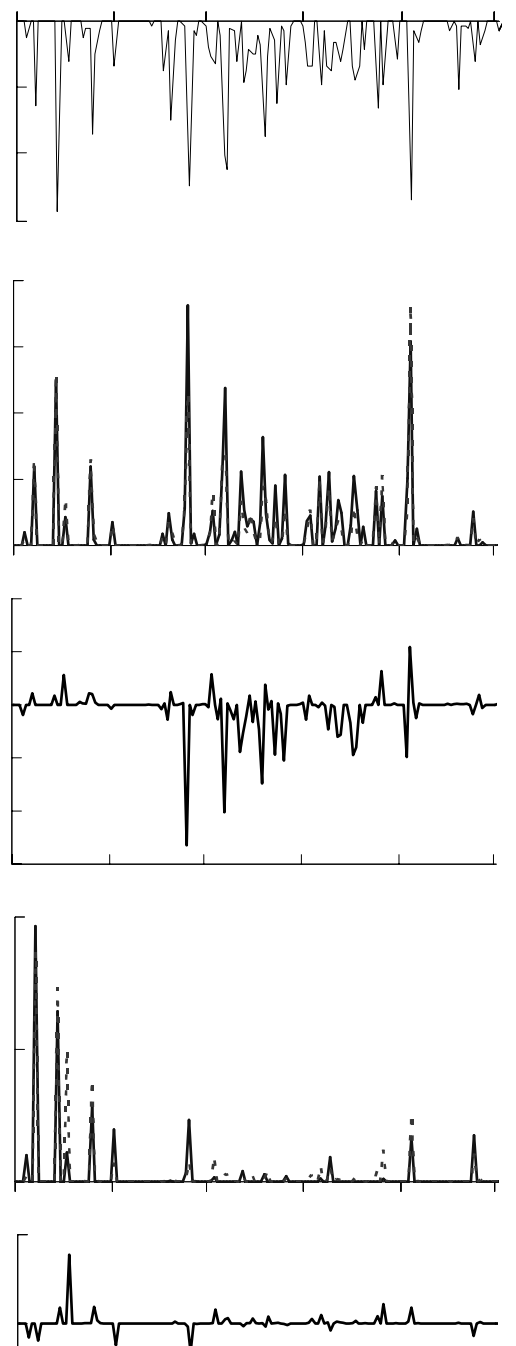

용

Figure 3. A comparison of hydrographs and sedigraphs between various models for cross-validation simulations and a snapshot at site 14 in Nepal from May to October in 1998 (i.e., 1998 wet season). Note that most of the rainfall, surface runoff, and soil erosion in the region occur during this period. Positive error indicates overprediction, and negative error indicates underprediction.

Australia for erosion). Note that a greater degree of improvement occurred for erosion simulation than for runoff simulation using the probability-based model compared with the conventional daily effective parameter model in both Nepal and Australia. A greater improvement in both runoff and erosion in Nepal than in Australia was also noticeable. It is possible that this could be related to the fact that the rainfall data on which the probability-based model was based were at finer temporal resolution in Nepal than in Australia (2-min tipping bucket data against 6-min chart digitized data). The general level of performance of the three models was also correlated between plots. That is the plots where the probability-based model performed best were also the plots where the subhourly and daily models performed best. There was also a tendency for the performance of the erosion predictions to be more consistent between calibration and validation for the probability-based model than for the subhourly model.

[30] A quantitative comparison of the three models was possible on the basis of the $C O E$ values (Table 3 ). These values show that in calibration simulations, for seventy percent of the sites, the probability-based model has $C O E \geq 0.87$ for runoff (against 0.85 for the subhourly model and 0.75 for the daily model), and $\geq 0.79$ for erosion (against 0.79 for the subhourly model and 0.36 for the daily model). Similarly in validation simulations, 

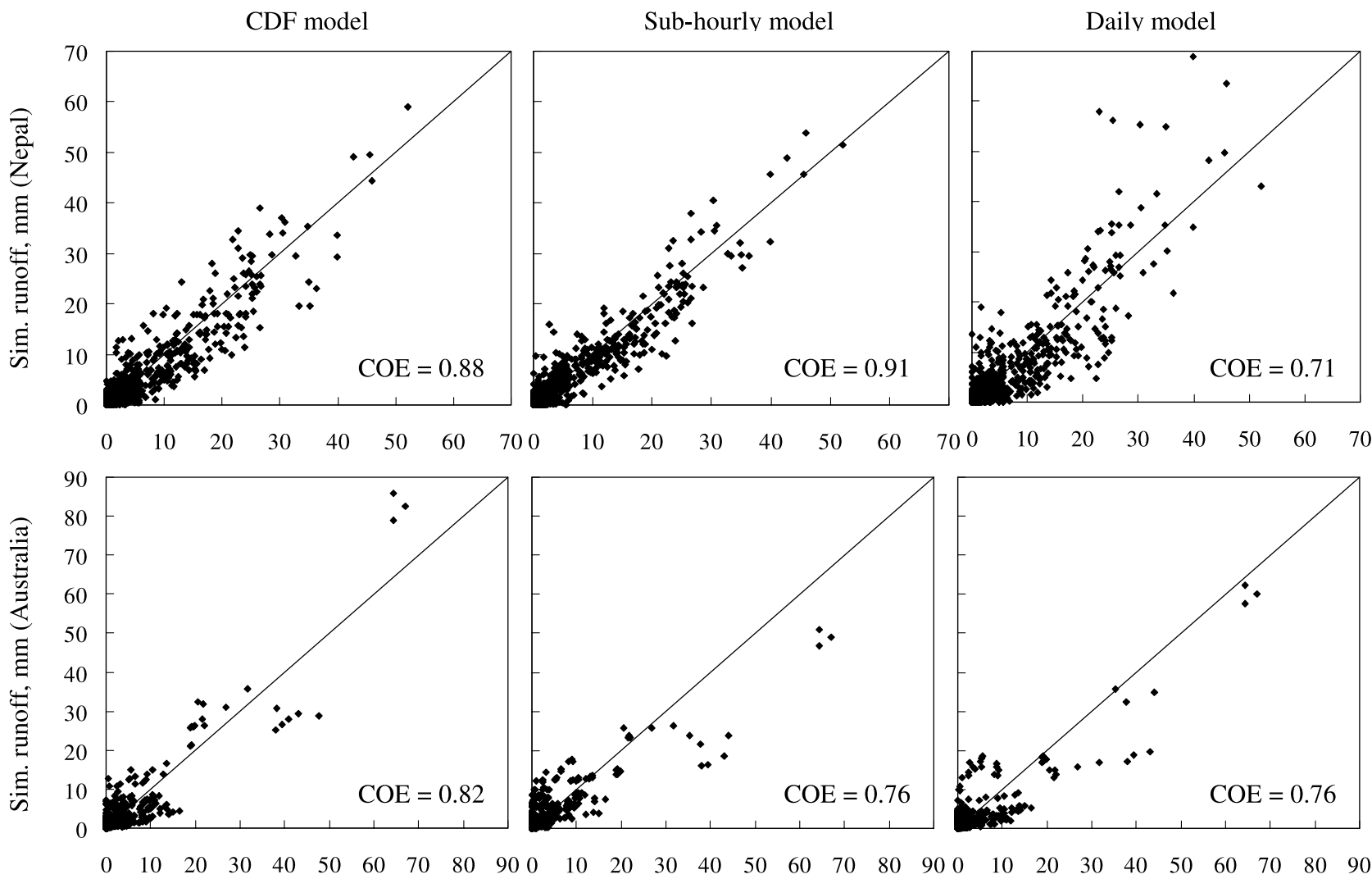

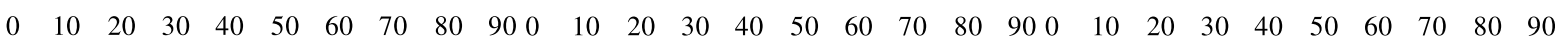

Obs. runoff, $\mathrm{mm}$
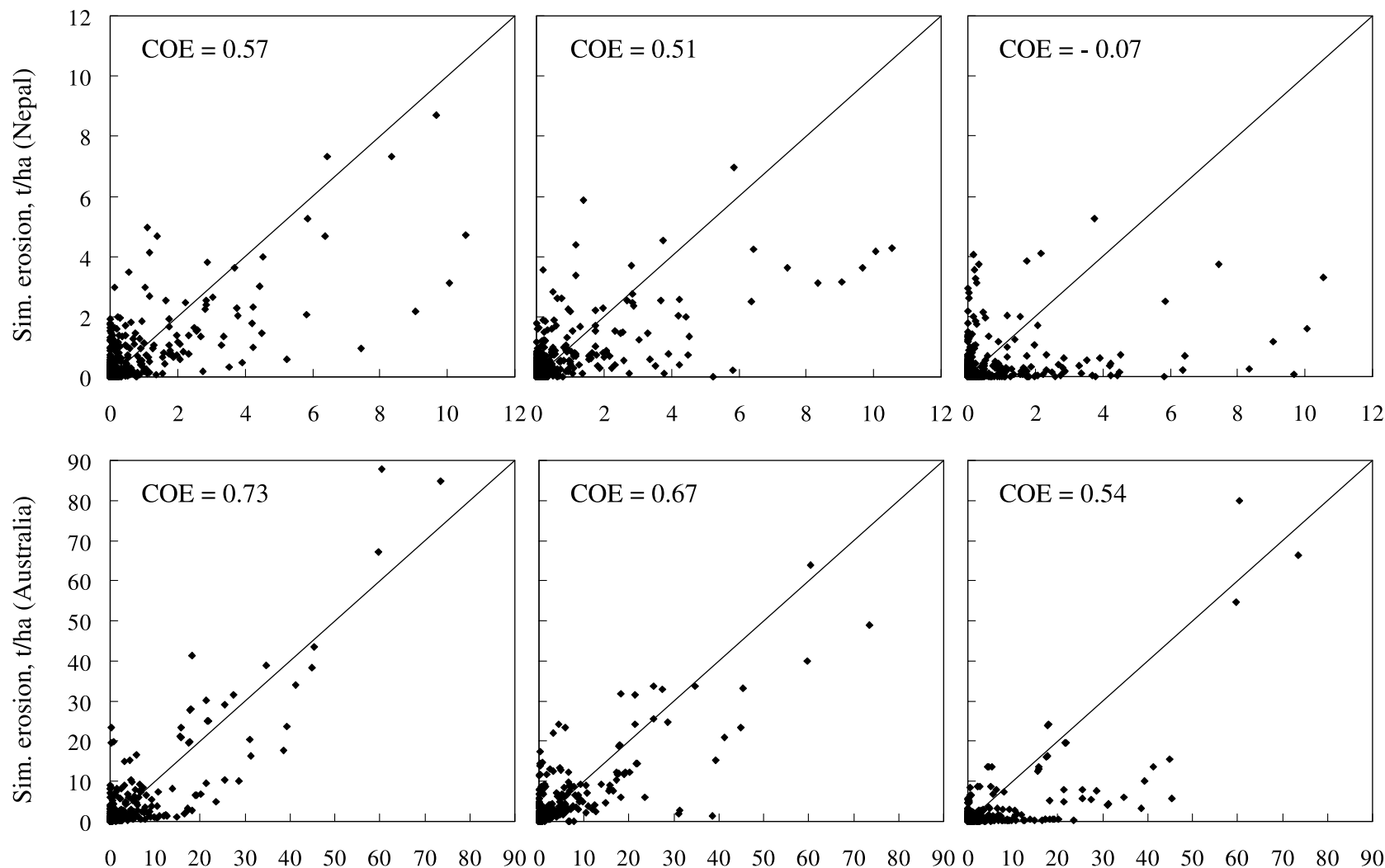

Obs. erosion, $\mathrm{t} / \mathrm{ha}$

Figure 4. Surface runoff and erosion prediction from cross-validation simulations collectively for 24 plot year data (i.e., $\mathrm{n}=365 \times 24=8760$ ) in the Nepalese sites and 18 plot year data (i.e., $\mathrm{n}=$ $365 \times 18=6570)$ in the Australian site. 

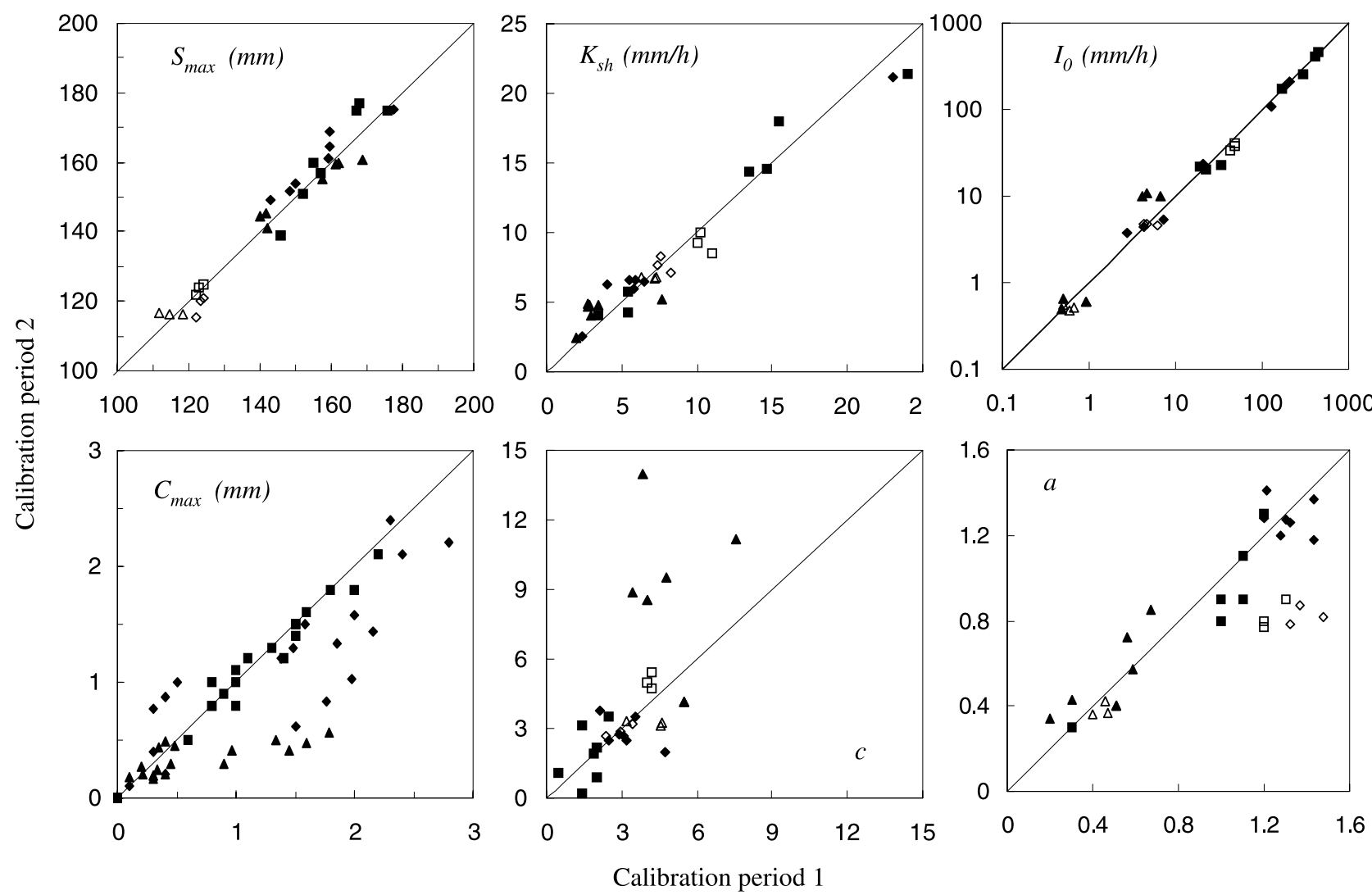

Figure 5. Comparison of runoff parameters between the two calibration periods. The first calibration period corresponds to 1997-1998 for Nepal and 1981-1983 for Australia, and the second calibration period corresponds to 1999-2000 for Nepal and 1984-1986 for Australia. Solid symbols are for Nepal, and open symbols are for Australia. Diamonds, subhourly model (2-min for Nepal and 6-min for Australia); triangles, daily model; squares, cdf model.

for fifty percent of the sites, the probability-based model has $C O E \geq 0.84$ for runoff (against 0.80 for the subhourly model and 0.74 for the daily model), and $\geq 0.65$ for erosion (against 0.56 for the subhourly model and -0.07 for the daily model). The probability-based model produced much better results for erosion at plot scales compared with those from the daily effective parameter model.

[31] In validation simulations, the probability-based model performed better than the subhourly model for three of the four cases, the exception being runoff in Nepal. It is interesting to note that the degree of degradation from calibration to validation was generally less for the probability-based model compared with the other two models. In terms of both bias and spread, the results of the probabilitybased model were similar to those of the subhourly model and much better than those of the daily effective parameter model. These observations are reflected in Figure 4 for both runoff and erosion simulations in Nepal and Australia. These statistics and visual observations indicated that the probability-based model was more robust and stable in validation simulations. Robustness here means the quality of the model performance in validation compared to calibration (i.e., a more robust model has less degradation of model efficiency in validation compared to calibration). This suggests that the probability-based modeling approach has potential for improved model prediction and transferability.
[32] There is a basic assumption in using the probabilitybased approach which is that for simulating daily (in this case) totals, the important feature of the subdaily rainfall intensity variation is its statistical distribution rather than the actual temporal sequence of rainfall intensity. We were unable to quantify the uncertainties associated with the simulated hydrographs and sedigraphs for the subhourly model or the simulated cdfs of runoff and erosion rates for the probability-based model since only daily runoff or erosion data were available. Rather all simulations were tested at the daily level using daily observations. Nevertheless, both the subhourly and the probability based models supported processes occurring at the timescale of minutes (the temporal distribution parameters of the probabilitybased model were derived from 2- or 6-min rainfall intensities). The fact that the subhourly model used the observed 2-min (or 6-min) rainfall intensity sequence and that the probability-based model and subhourly model produced similar simulation qualities at a daily timescale indicates that the variability of rainfall intensity is indeed of primary importance and the sequence is of secondary importance, at least for this model structure. This is very encouraging because in most practical model applications, we do not know the subdaily rainfall pattern. Having a daily time step model that is able to capture the dominant effect of subdaily variability of rainfall intensities on surface runoff and erosion prediction is a significant advance. 


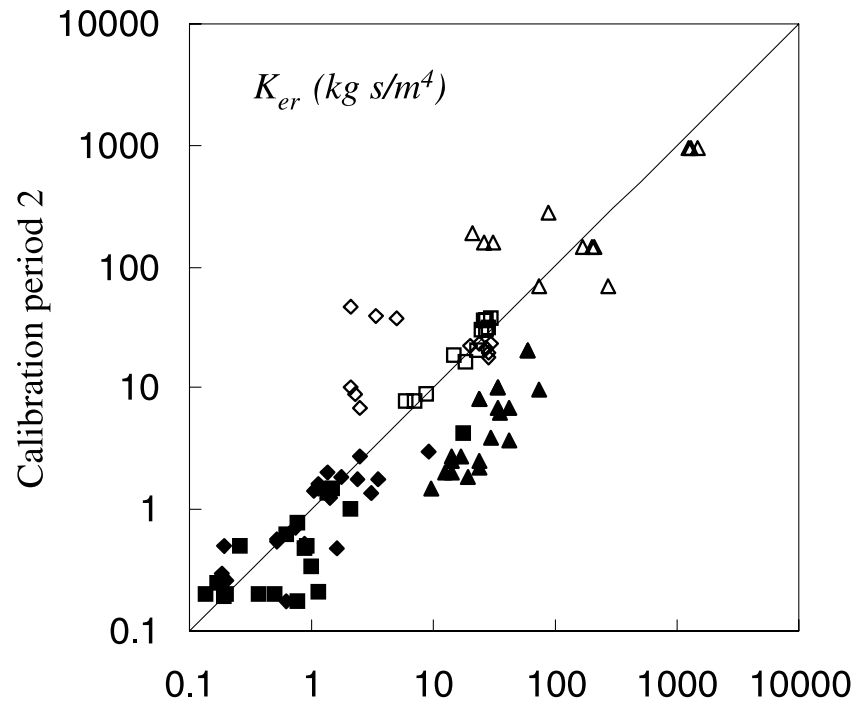

Calibration period 1

Figure 6. Comparison of erosion parameters between the two calibration periods. The first calibration period corresponds to 1997-1998 for Nepal and 1981-1983 for Australia, and the second calibration period corresponds to 1999-2000 for Nepal and 1984-1986 for Australia. Solid symbols are for Nepal, and open symbols are for Australia. Diamonds, subhourly model (2-min for Nepal and 6-min for Australia); triangles, daily model; squares, cdf model.

\subsection{Model Parameter Reliability and Plausibility}

[33] The runoff and erosion parameters obtained by calibrating the probability-based model for the two periods are shown in Figures 5 and 6. There are differences between sites (scatter along the 1:1 line), particularly for $C_{\max }, I_{0}$, and $K_{e r}$, differences in the typical parameter magnitudes between the models (all except $S_{\max }$ ) (clustering of triangles, squares and diamonds along the 1:1 line) and between the calibration periods (scatter about the 1:1 line).

[34] Between sites, $I_{0}$ varies by an order of magnitude depending mainly on the land use type (cultivated terraces in Nepal $=170$ to $450 \mathrm{~mm} / \mathrm{h}$, uncultivated barren land in Nepal $=20$ to $40 \mathrm{~mm} / \mathrm{h}$, and uncultivated barren land in Australia $=30$ to $50 \mathrm{~mm} / \mathrm{h}$ ). These values give an indication of the spatial variability of infiltration capacities at a time. $C_{\max }$ and $K_{e r}$ show strong seasonal variations. $C_{\max }$ ranges from $0.5 \mathrm{~mm}$ during the premonsoon to $2.2 \mathrm{~mm}$ during the monsoon season, while $K_{e r}$ is highest in the premonsoon season in Nepal (up to $20 \times 10^{6} \mathrm{~kg} \mathrm{~s} / \mathrm{m}^{4}$ ) and in the winter in Australia (up to $40 \times 10^{6} \mathrm{~kg} \mathrm{~s} / \mathrm{m}^{4}$ ). In terms of magnitude, parameter sets of the probability-based model and the subhourly model were similar but those of the daily model were very different. This indicated that the probability-based model parameters could be interpreted at the subtime step level as having similar physical meaning/significance to those in the subhourly model while those in the daily model are really daily effective parameters.

[35] Parameter stability and reliability is important for future prediction and for transferability to other catchments in the region. If the optimized parameter sets resulting from two independent calibration periods are similar, the param- eters are more likely to be stable over time (provided there are no significant changes to catchment characteristics such as land use). This should reduce the degree of uncertainty in the model output when applied to the future time periods. Given the data are for short periods (4 years in Nepal and 6 years in Australia) with no major changes in land use and management practices, the temporally fixed parameters $\left(S_{\max }, I_{0}, a, K_{s h}, c\right)$ were expected to be stable in time. The parameters with seasonality $\left(C_{\max }\right.$ and $\left.K_{e r}\right)$ were also expected to have similar values for the same season of different years. This meant that we expected them to be reasonably stable between the two calibration periods. In terms of stability, the probability-based model performed as well or better than the other two models for all the parameters. Interestingly, the probability-based model was able to produce more reliable parameters than the subhourly model, indicating the potential of probability-based approach for model transferability in time. This more robust parameter estimation is evidenced by the smaller scatter about the 1:1 line (Figures 5 and 6).

[36] Figures 5 and 6 show that the use of a short time step is not necessarily required to identify reliable and interpretable parameters, but rather that it is sufficient to build in the effects of the sub-time step variability. Given the similar (better in some cases) validation results and parameter values of the probability-based model to those of the subhourly model, it can be argued that the probability-based model is at least as robust and reliable as the subhourly model. This suggested that probability-based models could be as robustly parameterized and interpreted as the sub-time step models.

[37] The plausibility and physical significance of these parameters is difficult to objectively define, given the lack of directly measured parameter values. Nevertheless, we believe that the subhourly time step model is likely to be associated with more physically realistic parameter values than the daily time step model because the subhourly scale of the model better matches the timescale (in minutes) of the infiltration excess runoff generation and soil erosion processes. Therefore some indication of plausibility can be obtained by comparing the models. In terms of differences between the models, parameters of the probability-based model are generally much closer to the parameters of the subhourly model than to those of the daily model (Figure 5). In particular, it is noted that the limiting infiltration capacity $\left(I_{0}\right)$ and soil erodibility $\left(\mathrm{K}_{\mathrm{er}}\right)$ are very sensitive to model time step. Their values differ by more than an order of magnitude between the subhourly model and daily effective parameter model, but are much more consistent between the subhourly and the probability-based model (Figures 5 and 6; note $\log$ scale).

[38] Some field data were available for Nepalese sites that could be used to assess the plausibility of model parameters. The values of the limiting infiltration capacity parameter, $I_{0}$, were compared here with those obtained from the doublering infiltrometer test conducted in the same sites in Nepal (Figure 7). Owing to the effect of ponding and the smaller area (compared to experimental plots) of influence (outer ring $=600 \mathrm{~mm}$ and inner ring $=300 \mathrm{~mm}$ in diameter) in the double-ring infiltrometer values, it was not appropriate to compare these field measurements with the calibrated values of $I_{0}$ on a one-to-one basis [Kandel, 2003]. However, they could be compared in terms of their magnitude and 


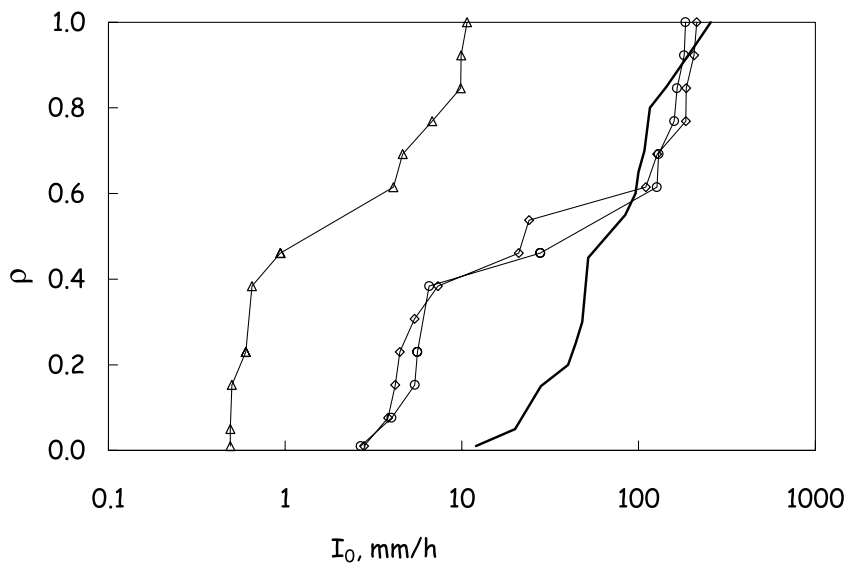

Figure 7. Spatial distribution of limiting infiltration rate $\left(I_{0}\right)$ parameter: Comparison between the modeled values and field measurements using double-ring infiltrometer test. Thin lines with symbols (diamonds, subhourly; triangles, daily; circles, cdf) show modeled parameters $(n=2$ calibration periods $\times 7$ plots $=14$ ), and thick line shows measured values $(\mathrm{n}=3$ replicates $\times 7$ plots $=21)$. The $I_{0}$ is spatially averaged infiltration, and the distributions are for values among plots.

general variability in space. In terms of the magnitude and general variation in space, the $I_{0}$ values from the probability-based model are closer to those from the subhourly model and field measured values while those from the daily effective parameter model appear unrealistically low (Figure 7).

\subsection{Discussion and Implications of Results}

[39] The probability distribution function approach is capable of representing the dominant controls of subdaily variability of rainfall, particularly for infiltration excess runoff and soil erosion. This is a significant improvement over the daily effective parameter model in rainfall-runofferosion modeling and the temporally distributed approach has the potential for general application in various hydrologic modeling and water resources studies. The approach is less constrained by data availability than an equivalent subtime step model, wherein fine resolution continuous data in the order of a few minutes is required for modeling soil erosion. Nevertheless, some fine resolution data is still needed to determine the parameters of the rainfall intensity distribution. However, there is a potential to use regionalized distribution parameters derived from a similar climatic region, given the experience of regionalization of stochastic rainfall models [e.g., Econopouly et al., 1990].

[40] This temporal probability distribution approach can be compared with similar spatial approaches. Many spatial modeling studies have shown that the averaging of processes and use of effective parameters is not appropriate and has a number of limitations [e.g., Beven, 1991] and the issue has been vigorously debated over the past one decade or so [e.g., Bashford et al., 2002; Beven, 1995; Blöschl and Sivapalan, 1995; Refsgaard, 1997; Refsgaard et al., 1999; Wooldridge et al., 2002]. It is also recognized that finer spatial modeling by increasing the grid resolution [e.g., Mamillapalli et al., 1996; Wood et al., 1988] alone cannot produce the best model performance if the processes are simulated at the lumped daily time step [e.g., Vázquez et al., 2002]. In addition to high computational requirements, the basic problem associated with high-resolution spatial models is the high spatial information requirement for specifying spatial patterns of parameter values [e.g., Andersen et al., 2001; Biftu and Gan, 2001]. For these reasons, the probability-based approach to representing unresolved variability has been attractive in the spatial context. This study has extended the application of probability-based approaches to the temporal domain for similar reasons. However, this has only been achieved at the plot scale.

[41] The next challenge is to integrate the space and time domains in probability-based models that focus on representing the characteristics of variability that dominate the response, for example, the spatiotemporal variability of atmospheric forcing (e.g., precipitation) and the spatial heterogeneity of the landscape (e.g., infiltration capacity and storage capacity). A major problem in evaluating the suitability of these models across the space-time scales will be the availability of field data at the right space and time resolution for verification of the model performance.

\section{Summary and Conclusions}

[42] Temporal resolution of computation is of fundamental importance in hydrologic and erosion modeling. It is commonly assumed that the effects of fine timescale processes can be adequately modeled using coarser model time steps (e.g., daily) with effective parameters derived by calibration. While this approach is partially successful in rainfall-runoff modeling, it can cause significant reductions in model performance when used for erosion modeling. This is because erosion depends mainly on the peak rainfall and runoff rates at short timescales, rather than the daily average rates as are used in the daily time step modeling.

[43] As an alternative, a probability-based approach for representing the effects of subdaily rainfall intensity variation within a daily time step model was developed and tested. The method used a cumulative distribution function (cdf) of rainfall intensities to represent the effect of subdaily temporal variability of daily rainfall. The rainfall intensity cdf was incorporated into the hydrologic and erosion algorithms to derive cdfs for surface runoff and erosion, which were then integrated to get the fluxes over the wet period in a day.

[44] While a lognormal distribution of rainfall intensities was used here, the scaling approach is general and any distribution function could be used. Some measured fine resolution rainfall data are required for the fitting of the distribution parameters. However, given the experience of regionalization of stochastic rainfall models [e.g., Econopouly et al., 1990], one option may be to use fine resolution data from a similar climatic region to determine regionalized distribution function parameters, thereby enabling application of the probability-based approach when only daily data are available.

[45] The distribution function model was tested using a split sample calibration and validation procedure at various sites in Nepal and Australia, and was shown to represent the dominant subdaily timescale controls, particularly for infiltration excess runoff and soil erosion response at the daily time step. Comparison of this model with other models demonstrated that (1) it performed better than the conventional daily effective parameter model, (2) it was almost as 
good as the subhourly model in calibration simulation while slightly better in validation simulation, particularly for erosion, (3) it was more robust and stable in validation simulations compared to both the subhourly and the daily effective parameter models, and (4) its calibration resulted in realistic parameter values similar to those of the subhourly model, which were more reliable and physically plausible than the daily effective parameters.

[46] The results of this study clearly show that the probability-based approach is able to successfully represent the dominant effect of sub-time step variability of rainfall intensity on infiltration excess runoff and soil erosion. The approach is less constrained by data availability than an equivalent sub-time step model, and has the potential for general application to various hydrologic modeling and water resources studies. Theoretically, the approach can be applied to spatially distributed models to account for the subgrid-scale variability. The real challenge is to integrate both spatially distributed models and temporally distributed models to have operational space-time distributed models to tackle the real world problems.

\section{Notation}

$\Delta t$ time step.

$\rho$ cumulative probability of rainfall intensity.

$\rho_{w}$ cumulative probability of rainfall intensity (wet period conditional).

$\mu$ mean of the natural log-transformed rainfall intensities (for wet part of the day).

$\sigma$ standard deviation of the log-transformed rainfall intensities (for wet part of the day).

$z($.) normal standard variates.

a nonlinearity factor for infiltration (optimized parameter).

c nonlinearity factor for subsurface drainage (optimized parameter).

$C_{0}$ initial canopy store.

$C_{\max }$ canopy interception storage capacity (optimized parameter).

$D_{e r}, d_{e r}(\rho)$ soil erosion rate, distribution of soil erosion rate.

$E_{a}, E_{p}$ total evapotranspiration rate (actual), potential evapotranspiration rate.

$E_{a c}, E_{a s}$ evaporation rate from canopy, evapotranspiration rate from land surface.

$I, i(\rho)$ infiltration rate, distribution of infiltration rate.

$I_{0}$ limiting infiltration rate under saturated conditions (optimized parameter).

$I_{p}$ potential infiltration rate (infiltration capacity).

$K_{e r} \quad$ soil erodibility (optimized parameter).

$K_{s h}$ saturated hydraulic conductivity (optimized parameter)

$K_{z}$ subsurface drainage rate.

$P, p(\rho)$ rainfall intensity, distribution of rainfall intensity.

$P_{t}, p_{t}(\rho)$ throughfall rate, distribution of throughfall rate.

$P_{\text {tot }}$ total daily rainfall.

$P_{w}$ wet period mean rainfall intensity.

$R, r(\rho)$ total runoff rate, distribution of total runoff rate.
$R_{I E}, r_{I E}(\rho)$ runoff rate, distribution of runoff rate (infiltration excess).

$R_{S E}, r_{S E}(\rho)$ runoff rate, distribution of runoff rate (saturation excess).

$S, S_{0}, S_{f c}$ soil store, initial soil store, field capacity soil store.

$S_{f}$ slope factor.

$S_{\max }$ soil storage capacity (optimized parameter).

$w$ wet fraction or raining proportion of the time step (a day here).

[47] Acknowledgments. The authors thank the People and Resource Dynamics Project (PARDYP) of the International Centre for Integrated Mountain Development (ICIMOD), Kathmandu, Nepal, for kind collaboration and for providing Nepalese data set. The authors thank Bofu Yu, The Griffith University, Australia, for generously providing Australian data set. The authors also wish to thank the anonymous reviewers and the editors for their thoughtful and constructive comments to improve the manuscript.

\section{References}

Andersen, J., J. C. Refsgaard, and K. H. Jensen (2001), Distributed hydrological modelling of the Senegal River Basin-Model construction and validation, J. Hydrol., 247, 200-214.

Bashford, K. E., K. J. Beven, and P. C. Young (2002), Observational data and scale-dependent parameterizations: Explorations using a virtual hydrological reality, Hydrol. Processes, 16, 293-312.

Bathurst, J., B. Lukey, J. Sheffield, R. Hiley, and N. Mathys (1998), Modelling badlands erosion with SHETRAN at Draix, southeast France, in Modelling Soil Erosion, Sediment Transport and Closely Related Hydrological Processes, IAHS Publ., 249, 129-136.

Bennett, J. P. (1974), Concepts of mathematical modeling of sediment yield, Water Resour. Res., 10, 299-303.

Beven, K. (1991), Scale considerations, in Recent Advances in the Modelling of Hydrologic Systems, edited by D. Bowles and P. O'Connell, pp. 357-371, Springer, New York.

Beven, K. (1993), Prophecy, reality and uncertainty in distributed hydrological modelling, Adv. Water Resour., 16(1), 41-51.

Beven, K. (1995), Linking parameters across scales-Subgrid parameterizations and scale dependent hydrological models, Hydrol. Processes, 9 , $507-525$.

Beven, K. J., and M. J. Kirkby (1979), A physically-based variable contributing area model of basin hydrology, Hydrol. Sci. Bull., 24, 43-69.

Biftu, G. F., and T. Y. Gan (2001), Semi-distributed, physically based, hydrologic modelling of the Paddle River Basin, Alberta, using remotely sensed data, J. Hydrol., 244, 137-156.

Blöschl, G., and M. Sivapalan (1995), Scale issues in hydrological modelling: A review, Hydrol. Processes, 9, 251-290.

Boughton, W. (2000), A model for disaggregating daily to hourly rainfalls for design flood estimation, Tech. Rep. 00/15, Coop. Res. Cent. for Catchment Hydrol., Melbourne, Victoria, Australia.

Cameron, D., K. Beven, and J. Tawn (2001), Modelling extreme rainfalls using a modified random pulse Bartlett-Lewis stochastic rainfall model (with uncertainty), Adv. Water Resour., 24(2), 203-211.

Chiew, F., Q. J. Wang, F. McConachy, R. James, W. Wright, and G. deHoedt (2002), Evapotranspiration maps for Australia, paper presented at 27th Hydrology and Water Resources Symposium, Inst. of Eng. Aust., Melbourne, Victoria.

Collins, R., A. Dickinson, and R. Johnson (1998), The use of GIS and remote sensing techniques to predict erosion in the Nepal Middle Hills, in Soil Erosion at Multiple Scales, edited by F. W. T. Penning de Vries, F. Agus, and J. Kerr, pp. 303-315, CAB Int., Wallingford, U. K.

Connolly, R. D., J. Schirmer, and P. K. Dunn (1998), A daily rainfall disaggregation model, Agric. For. Meteorol., 92(2), 105-117.

Cook, H. (1936), The nature and controlling variables of the water erosion process, Soil Sci. Soc. Am. Proc., 1, 487-494.

David, W., and C. Beer (1975), Simulation of soil erosion-part I. Development of a mathematical erosion model, Trans. ASAE, 18(1), 126-129, 133.

Downer, C. W., F. L. Ogden, W. D. Martin, and R. S. Harmon (2002), Theory, development, and applicability of the surface water hydrologic model CASC2D, Hydrol. Processes, 16, 255-275.

Econopouly, T. W., D. R. Davis, and D. A. Woolhiser (1990), Parameter transferability for a daily rainfall disaggregation model, J. Hydrol., 118, $209-228$. 
Ekern, P. (1950), Raindrop impact as the force initiating soil erosion, Soil Sci. Soc. Am. Proc., 15, 7-10.

Ellison, W. (1944), Studies of raindrop erosion, Agric. Eng., 25, 131-136, $181-182$.

Flanagan, D., G. Foster, and W. Moldenhauer (1988), Storm pattern effect on infiltration, runoff, and erosion, Trans. ASAE, 31(2), 414-420.

Foster, G., and L. Meyer (1975), Mathematical simulation of upland erosion using fundamental erosion mechanics, in Present and Prospective Technology for Predicting Sediment Yields and Sources, Proceedings of the 1972 Sediment-Yield Workshop, ARS-S-40, pp. 190-207, Sediment. Lab., U.S. Agric. Res. Serv., Oxford, Miss.

Foster, G., L. Meyer, and C. Onstad (1977), An erosion equation derived from basic erosion principles, Trans. ASAE, 20(4), 678-682.

Foster, G., D. Flanagan, M. Nearing, L. Lane, L. Risse, and S. Finkner (1995), Hillslope erosion component, in USDA Water Erosion Prediction Project: Hillslope Profile Model Documentation, NSERL Rep. 2, edited by L. Lane and M. Nearing, pp. 11.11-11.12, Natl. Soil Erosion Lab., West Lafayette, Indiana.

Foster, R., and G. Martin (1969), Effect of unit weight and slope on erosion, Proc. Irrig. Drain. Div. Am. Soc. Civ. Eng., 95(IR4), 551-561.

Ghidey, F., and E. E. Alberts (1996), Comparison of measured and WEPP predicted runoff and soil loss for midwest claypan soil, Trans. ASAE, 39(4), 1395-1402.

Glasbey, C. A., G. Cooper, and M. B. McGechan (1995), Disaggregation of daily rainfall by conditional simulation from a point-process model, J. Hydrol., 165, 1-9.

Grayson, R. B., G. Blöschl, R. D. Barling, and I. D. Moore (1993), Process, scale and constraints to hydrological modelling in GIS, in Application of Geographic Information Systems in Hydrology and Resources Management, edited by K. Kovar and H. P. Nachtnebel, IAHS Publ., 211, 83-92.

Hairsine, P., and C. Rose (1992), Modelling water erosion due to overland flow using physical principles: 1. Uniform sheet flow, Water Resour. Res., 28, 237-243.

Hawkins, R., and T. Cundy (1987), Steady-state analysis of infiltration and overland flow for spatially varied hillslopes, Water Resour. Bull., 23(2), $251-256$.

Hershenhorn, J., and D. Woolhiser (1987), Disaggregation of daily rainfall, J. Hydrol., 95, 299-322.

Kandel, D. D. (1998), Soil erosion studies in Jhikhu khola and Yarsha khola watersheds in Nepal, annual technical progress report of PARDYP-1997, Dep. of Soil Conserv. and Watershed Manage., Katmandu, Nepal.

Kandel, D. D. (2003), Representation of short time-scale processes in daily time-step surface runoff and erosion modelling, Ph.D. thesis, 400 pp., Univ. of Melbourne, Melbourne, Victoria, Australia.

Kandel, D., A. Western, R. Grayson, and H. Turral (2001), Testing current generation soil erosion models at $2 \mathrm{~min}$ and daily scales using plot scale data from a mid-hill catchment of Nepal, in Proceedings of the International Congress on Modelling and Simulation (MODSIM 2001), edited by R. Vertessy, pp. 365-370, Modell. and Simul. Soc. of Aust. and N. Z., Canberra.

Kandel, D., A. Western, R. Grayson, and H. Turral (2002), Surface runoff modelling: part 1. Testing at fine timescale for scaling upto daily scale, paper presented at 27th Hydrology and Water Resources Symposium, Inst. of Eng. Aust., Melbourne, Victoria.

Kandel, D., A. Western, R. Grayson, and H. Turral (2004), Process parameterization and temporal scaling in surface runoff and erosion modelling, Hydrol. Processes, 18, 1423-1446.

Kinnell, P., and L. Risse (1998), USLE-M: Empirical modelling rainfall erosion through runoff and sediment concentration, Soil Sci. Soc. Am. J., $62,1667-1672$

Kirkby, M. (2001), Modelling the interactions between soil surface properties and water erosion, Catena, 46(2-3), 89-102.

Kirkby, M. J., R. Abrahart, M. D. McMahon, J. Shao, and J. B. Thornes (1998), MEDALUS soil erosion models for global change, Geomorphology, 24(1), 35-49.

Liebenow, A., W. Elliot, J. Laflen, and K. Kohl (1990), Interrill erodibility: Collection and analysis of data from cropland soils, Trans. ASAE, 33(6), $1882-1888$

Mamillapalli, S., R. Srinivasan, J. Arnold, and B. Engel (1996), Spatial variability in basin scale hydrologic modelling, paper presented at Third International Conference/Workshop on Integrating GIS and Environmental Modelling, U.S. Natl. Cent. for Geogr. Inf. and Anal., Santa Fe, N. M.

Mertens, J., D. Raes, and J. Feyen (2002), Incorporating rainfall intensity into daily rainfall records for simulating runoff and infiltration into soil profiles, Hydrol. Processes, 16, 731-739.

Meyer, L., and E. Monke (1965), Mechanics of soil erosion by rainfall and overland flow, Trans. ASAE, 8(4), 572-577.
Meyer, L., and W. Wischmeier (1969), Mathematical simulation of the process of soil erosion by water, Trans. ASAE, 12(6), 754-762.

Meyer, L., G. Foster, and M. Romkens (1975), Origin of eroded soil from upland slopes, in Present and Prospective Technology for Predicting Sediment Yields and Sources, Proceedings of the 1972 Sediment-Yield Workshop, ARS-S-40, pp. 177-189, Sediment. Lab., U.S. Agric. Res. Serv., Oxford, Miss.

Moore, R. J. (1985), The probability-distributed principle and runoff production at point and basin scales, Hydrol. Sci. J., 30(2), 273-297.

Moore, R. J., and R. T. Clarke (1981), A distribution function-approach to rainfall runoff modelling, Water Resour. Res., 17(5), 1367-1382.

Moore, R. J., and R. T. Clarke (1983), A distribution function-approach to modelling basin sediment yield, J. Hydrol., 65, 239-257.

Morgan, R., J. Quinton, R. Smith, G. Govers, J. Poesen, K. Auerswald G. Chisci, D. Torri, and M. Styczen (1998), The European Soil Erosion Model (Eurosem) - A dynamic approach for predicting sediment transport from fields and small catchments, Earth Surf. Processes Landforms, 23(6), 527-544

Nash, J., and J. Sutcliffe (1970), River flow forecasting through conceptual models, part1: A discussion of principles, J. Hydrol., 10, 282-290.

Neal, J. (1938), Effect of degree of slope and rainfall characteristics on runoff and soil erosion, Agric. Eng., 19(5), 213-217.

Nelder, J., and R. Mead (1965), A simplex method for function minimization, Comput. J., 7, 308-313.

Refsgaard, J. C. (1997), Parameterization, calibration and validation of distributed hydrological models, J. Hydrol., 198, 69-97.

Refsgaard, J. C., M. Thorsen, J. B. Jensen, S. Kleeschulte, and S. Hansen (1999), Large scale modelling of groundwater contamination from nitrate leaching, J. Hydrol., 221, 117-140.

Rose, C., and B. Yu (1998), Dynamic process modelling of hydrology and soil erosion, in Soil Erosion at Multiple Scales, edited by F. P. deVries, F. Agus, and J. Kerr, pp. 269-286, CAB Int., Wallingford, U. K.

Sivapalan, M., and E. Wood (1986), Spatial heterogeneity and scale in the infiltration response of catchments, in Scale Problems in Hydrology, edited by V. Gupta, I. Rodriguez-Iturbe, and E. Wood, pp. 81-106, Springer, New York.

Sivapalan, M., and R. A. Woods (1995), Evaluation of the effects of general circulation model's subgrid variability and patchiness of rainfall and soi moisture on land surface water balance fluxes, in Scale Issues in Hydrological Modelling, edited by J. D. Kalma and M. Sivapalan, pp. $453-$ 473, John Wiley, Hoboken, N. J.

Smith, D., and W. Wischmeier (1957), Factors affecting sheet and rill erosion, Eos Trans. $A G U, 38(6), 889,896$.

Socolofsky, S., E. Adams, and D. Entekhabi (2001), Disaggregation of daily rainfall for continuous watershed modelling, J. Hydrol. Eng., 6(4), 300-309.

Thornthwaite, C. (1948), An approach toward a rational classification of climate, Geogr. Rev., 38, 55-94.

Vázquez, R., L. Feyen, J. Feyen, and J. Refsgaard (2002), Effect of grid size on effective parameters and model performance of the MIKE-SHE code, Hydrol. Processes, 16, 355-372.

Williams, J. (1975), Sediment yield prediction with universal equation using runoff energy factor, in Present and Prospective Technology for Predicting Sediment Yields and Sources, Proceedings of the 1972 Sediment-Yield Workshop, ARS-S-40, pp. 244-252, Sediment. Lab., U.S Agric. Res. Serv, Oxford, Miss.

Wischmeier, W. (1972), Upslope Erosion Analysis. Environmental Impact on Rivers, Water Resour. Publ., Highlands Ranch, Colo.

Wischmeier, W., and D. Smith (1958), Rainfall energy and its relationship to soil loss, Eos Trans. AGU, 39(2), 285, 291.

Wischmeier, W., and D. Smith (1965), Predicting Rainfall Erosion Losses From Cropland East of the Rocky Mountains, Agric. Handb. 282, 47 pp. U.S. Dep. of Agric., Washington, D. C.

Wischmeier, W., and D. Smith (1978), Predicting Rainfall Erosion LossesA Guide to Conservation Planning, Agric. Handb. 537, U.S. Gov. Print. Off., Washington, D. C.

Wood, E. F., M. Sivapalan, K. J. Beven, and L. E. Band (1988), Effects of spatial variability and scale with implications to hydrologic modelling, J. Hydrol., 102, 28-47.

Wood, E. F., D. F. Lettenmaier, and V. G. Zartarian (1992), A land-surface hydrology parameterization with sub-grid variability for general circulation models, J. Geophys. Res., 97, 2717-2728.

Wooldridge, S. A., J. D. Kalma, S. W. Franks, and G. Kuczera (2002), Model identification by space-time disaggregation: A case study from eastern Australia, Hydrol. Processes, 16(2), 459-477.

Young, R., and J. Wiersma (1973), The role of rainfall impact in soil detachment and transport, Water Resour. Res., 9, 1629-1639. 
Yu, B., and C. W. Rose (1999), Application of a physically based soil erosion model, GUEST, in the absence of data on runoff rates: I. Theory and methodology, Aust. J. Soil Res., 37, 1-11.

Yu, B., and C. J. Rosewell (2001), Evaluation of WEPP for runoff and soil loss prediction at Gunnedah, NSW, Australia, Aust. J. Soil Res., 39, $1131-1145$

Yu, B., C. Rose, K. Coughlan, and B. Fentie (1997), Plot-scale rainfallrunoff characteristics and modelling at six sites in Australia and southeas Asia, Trans. ASAE, 40(5), 1295-1303.
Yu, B., U. Cakurs, and C. Rose (1998), An assessment of methods for estimating runoff rates at the plot scale, Trans. ASAE, 41(3), 653-661.

R. B. Grayson, D. D. Kandel, and A. W. Western, Cooperative Research Centre for Catchment Hydrology and Centre for Environmental Applied Hydrology, Department of Civil and Environmental Engineering, University of Melbourne, Melbourne, Vic 3010, Australia. (ddkandel@ civenv.unimelb.edu.au) 


\section{University Library}

\section{- M M N E R VA A gateway to Melbourne's research publications}

Minerva Access is the Institutional Repository of The University of Melbourne

Author/s:

Kandel, DD;Western, AW;Grayson, RB

Title:

Scaling from process timescales to daily time steps: A distribution function approach

Date:

2005-02

Citation:

Kandel, D. D., Western, A. W. \& Grayson, R. B. (2005). Scaling from process timescales to daily time steps: A distribution function approach. Water Resources Research, 41 (2), https://doi.org/10.1029/2004WR003380.

Persistent Link:

http://hdl.handle.net/11343/297414 